\title{
Evaluation of Alternative Options for the Irrigation Aqueduct of the Cavallino Peninsula Using the MULINO Approach
}

\author{
Carlo Giupponi ${ }^{1^{*}}$, Jacobo Féas ${ }^{2}$, Adrian Stanica ${ }^{3}$, Lorenzo Furlan ${ }^{4}$ \\ ${ }^{1}$ Dipartimento di Produzione Vegetale, Università di Milano \\ Via Celoria 2, 20133 Milano, Italy; and Fondazione Eni Enrico Mattei \\ ${ }^{2}$ Departament of Business Organization and Commercialization, University of Santiago de Compostela \\ Av do Burgo S/N. 15782, Santiago de Compostela, España; and Fondazione Eni Enrico Mattei \\ ${ }^{3}$ National Institute for Marine Geology and Geoecology - GeoEcoMar \\ str. Dimitrie Onciul 23-25, sect. 2, Bucharest, Rumania; and Fondazione Eni Enrico Mattei \\ ${ }^{4}$ Consorzio di Bonifica Basso Piave \\ Piazza Indipendenza 25, 30027 San Donà di Piave (Ve), Italy
}

\begin{abstract}
In the present article we analyse the problem and the effects of changes in irrigation technology that affect a farmer community in the Cavallino Peninsula in the northeast of Italy. The obligation of closing and sealing the wells, which are currently used in the area for irrigation purposes, is due to a national law aimed at preserving the groundwater resources and preventing subsidence phenomena in the Venice area. The enforcement of this law implies that the regional administration is obliged to provide farmers with sufficient water supply for their agricultural activity. The methodology developed within the MULINO Project was used in this analysis, to test the potentials of a decision support system tool (mDSS) developed by the project. Firstly, the decision context was analysed and, as result, the problem was subdivided in two more specific sub problems: one related with water abstraction and the other related with water distribution. In order to build the decisional model, the opinions of experts and the preferences of the stakeholders were taken into account in different phases of the process. The results allowed the competent administration to identify the stakeholders' main concerns about the development of a new irrigation system and to develop strategies to cope with them. The quality of the water supplied and the economic effects of the change in the irrigation system were the main issues dealt with in this process. The application of the MULINO approach and DSS tool added efficiency and transparency to the decision making process, by allowing the elicitation of opinions and preferences of all the actors involved in the process, and demonstrating that, notwithstanding the different viewpoints and interests, a general consensus could be reaches on a single management option.
\end{abstract}

Key-words: irrigation, decision support system, multicriteria analysis, public participation.

\section{Introduction}

Like environmental planning in general, Integrated Water Resources Management (IWRM) is usually characterised by the involvement of numerous decision-makers operating at different levels and of a large number of stakeholders with conflicting preferences and different value judgments (Lahdelma et al., 2000). This makes the development of policy implementation strategies and decision-making in the context of IWRM a very complex issue, since it also requires a broader integration with other sectors such as environment, energy, industry, agriculture and tourism.
Adequate methodologies and tools are therefore necessary in order to measure how a specific policy meets the objectives of the various actors, to identify and understand the possible conflicts that may arise between these actors and, finally, to design possible paths and courses of action to arrive at a sustainable solution. Science and research are called upon to play a stronger and more policy relevant role to find adequate methodologies and tools (ICSU, 2002).

The European Water Framework Directive (WFD) (EC, 2000) specifically addresses public information and consultation in Article 14. The 
Member States have to involve the public in the implementation of the Directive by publishing specific information relevant to the River Basin Plans and by being open to the public's comments about the planning process. Member States should also encourage the active involvement of all the interested parties, which requires more than the publication of information, and this is a novelty for some European countries, including Italy.

EU Member States with little experience in public participation, may find the implementation of the WFD principles very challenging. Establishing new lines of communication and the facilities for collecting and recording public opinions may be costly, and such procedures may be incompatible with current planning approaches. Moreover, there may be resistance to what may seem like a step towards a redistribution of power that threatens the freedom of individuals or organisations to make decisions in a non-transparent way.

Clear roles played by the various actors are a prerequisite for an effective participatory process. The decision maker is situated in the centre of the decision-making process and has the institutional power and responsibility to select and implement a solution for a specific problem. Stakeholders are all those that may influence or will be influenced by the consequences of the solution adopted and implemented by the decision maker. The analyst, who is the person/group that helps and guides the decision maker to analyse and represent the stakeholders' preference structures is also often present. This latter role is typically played by scientists in applied research.

In order to facilitate the active involvement of all the stakeholders in water decision problems there is a challenge to be faced: the integration of scientific knowledge and public participation. This is not an easy task.

Indeed, once the crucial importance of public participation in the decision-making process in IWRM has been recognised, the following step must be to clarify how public participation, decision-making and scientific knowledge can be integrated. For this integration, all the meaningful information has to be collected, structured and presented in an understandable way to help decision makers integrate all the actors involved in the decision-making process and all the scientific knowledge available. Decision
Support Systems (DSSs) are the tools the scientific literature proposes to cope with such problems in the management decision processes. Several DSSs have been developed in recent years to satisfy this need, for various kinds of water resource planning and management such as prevention of water shortages (drought), surpluses (floods) and water impairment (pollution). Examples of such DSS tools are WATERWARE (Jamieson and Fedra, 1996), AQUATOOL (Andreu et al., 1996), NELUP (O'Callaghan, 1995), FLOODSS (Catelli et al., 1998), DSSIPM (da Silva et al., 2001), STEELGDSS (Ostrowski, 1997).

Another recently released DSS is mDSS, developed by the project MULINO (MULti-sectoral, INtegrated and Operational Decision Support System for Sustainable Use of Water Resources at the Catchment Scale), funded under the Fifth Framework Programme of the European Union ${ }^{1}$. The mDSS tool has been developed with the specific aim to assist water authorities improve the quality of decision-making and achieve a truly integrated approach envisaging socio-economic and environmental modelling techniques and multi-criteria decision methods, with specific reference to the requirements of the EU Water Framework Directive.

This paper reports the results of the application of the MULINO methodology and DSS tool to the "Cavallino" case study (northeast Italy), one of the test sites chosen by the project to support the development and testing of the approach proposed.

\section{Materials and methods}

\subsection{The case study}

Until now, the water used to irrigate the market gardens of the Cavallino peninsula has been

\footnotetext{
1 The MULINO Consortium: Fondazione ENI Enrico Mattei (Italy), Universidade Atlântica (Portugal), Université Catholique de Louvain (Belgium), Silsoe Research Institute (UK), European Commission Joint Research Centre, Centre for Advanced Studies, Research and Development in Sardinia, (Italy), Research Institute of Soil Science and Agrochemistry of Bucharest (Romania), Fundatia Pentru Tehnologia Informatiei Aplicate in Mediu, Agricultura si Schimbari Globale (Romania), Institute of Water and Environment, Cranfield University (UK).
} 
extracted from private wells. This system, based on groundwater abstraction, must be abandoned as a result of an Italian national law (DL $29 / 3 / 1995 \mathrm{n}$. 96) that prescribes the sealing of all the wells in order to protect groundwater resources and to avoid the subsidence problems that affect the Venice area. According to the cited law, the "Basso Piave" Irrigation and Reclamation Board (BPB) was given the responsibility to design a new public irrigation system, drawing water from the Sile River and distributing it to the farms through a pressurised network.

The process of implementation of the legislative prescription has been slowed down by political debates and social conflicts with farmers' associations opposing the change of current systems. Although the water from the river was shown to be of good quality, farmers (whose main activity is horticulture) were distrustful and asked for further investments in water treatment plants. This opposition was seen, at least by some of the interested parties, as a strategy for stopping, or at least delaying the implementation of the legislative prescription.

Given the complexity of the local situation, the Land Reclamation Board decided to participate in the activities of the MULINO Project and to contribute by including the Cavallino Aqueduct in the list of the project's case stud- ies, in which a new decision support system was to be developed and tested in diverse decision processes in Europe. In the present case the mDSS tool was used to assess the aqueduct project and to evaluate whether additional water treatment plants were or were not a good further solution.

Cavallino is an elongated and thin peninsula that stretches between the Lagoon of Venice (Italy) to the North and the Adriatic Sea to the South (see Figure 1). The landscape is flat and it is made of 2500 ha of reclaimed land (fossil coastal dunes converted to agricultural land), half of them cultivated. The Cavallino area is part of the wider drainage basin that flows into the lagoon. The soil is sandy, mainly cultivated with horticultural crops, maize and soybean. The wells used for the water abstraction are deep. The water used for irrigation is located in a series of sandy aquifers at depths varying between 80 and $200 \mathrm{~m}$ below the mean sea level.

Due to the complexity of the problem analysed, the decisions were formalised and structured in two separate steps: the first one related to the choice of water abstraction and distribution systems and the second related to the possible treatment of the irrigation water, in order to cope with possible qualitative problems.

The first step was formalised according to the Environmental Impact Assessment (EIA)

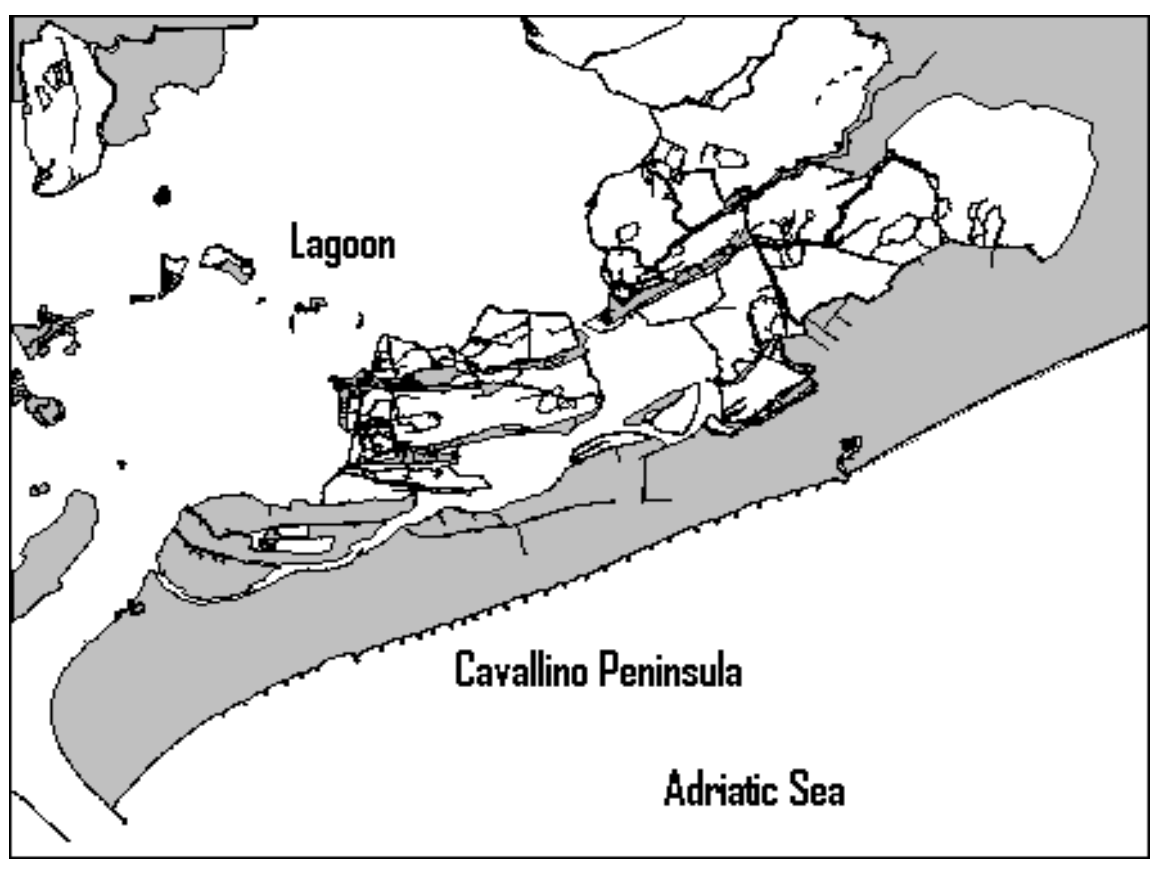

Figure 1 . The study area. 
dossier required by the regional administration as part of the project documentation and previously drafted by the BPB. The EIA dossier provided information for the definition of the alternative options and the evaluation criteria to be considered for the first step, to be formalised in mDSS, as described in Section 3, in order to provide a further contribution to the analysis and communication of the problem with the interested parties.

Considering that three possible alternatives were available for water abstraction and three for distribution, the result is a theoretical combination of nine alternative options. But, following the indications of the EIA and the interviews with the project designer, only six options could be considered as technically efficient in the paretian sense (Table 1). For example in order to utilise the Existing branch point (Option 3 concerning abstraction), there is no other possibility than to use a PVC pipe network (option B concerning distribution), because in this option the network must be lain beneath the Venetian Lagoon. Only the combined option 3B was therefore considered in the multi-criteria analysis.

Concerning the criteria to be considered for the ranking of the alternative options in step 1, the EIA dossier also provided the quantification of the performances of the various options, previously acquired by the BPB by interviewing experts, who provided judgments in a scale ranging between -3 for the worst judgement, and +3 , for the best judgement.

While the first step was already conducted by the BPB, the definition of the second decisional step was elaborated within the research project and adopted the methods proposed by the MULINO approach, to innovate the usual approach to decision making by emphasising the involvement of the interested actors, through the implementation of participatory processes. Two main activities were put into action to facilitate the involvement of the interested parties: i) a farm survey conducted with a questionnaire (Q1) aimed at investigating the current agricultural systems of the Cavallino Peninsula and the farmers' perception of the project in question (Dridani, 2002); and ii) the stakeholder analysis conducted with another questionnaire (Q2) compiled by means of interviews with a more diversified group of actors, including, besides farmers, representatives of in-
Table 1. The Options - Cavallino.

\begin{tabular}{lll}
\hline Option & Abstraction location & Distribution system \\
\hline 1A & Mouth of Sile river & Cement pipe network \\
1B & Mouth of Sile river & PVC pipe network \\
2A & Existing pumping station & Cement pipe network \\
2B & Existing pumping station & PVC pipe network \\
2C & Existing pumping station & Existing open canal \\
3B & Existing branch point & PVC pipe network \\
\hline
\end{tabular}

stitutions and associations at various levels municipal to regional).

As shown by the outcomes of Q1, farmers quite often oppose the re-organisation plan for two main reasons: concerns about the availability of water and concerns about its quality. Regarding the first problem, technical agronomic investigations demonstrated that the vast majority of farms will maintain or increase the current volumes of available irrigation water, but with a restriction: differently from the current situation (water available on demand from the private wells) farmers would be obliged to re-organise irrigation with turns of a few hours per day.

Possible limitations deriving from the turns have a rather simple technical solution in building small farm reservoirs, that can be managed with the pumps currently used for the wells. The water quality issue, instead, appeared to be more complex and was therefore deeply investigated in the second step of the decisional process. The analysis of the possible technical solutions in terms of different types of purification systems, allowed the identification of four possible responses to the problem:

- NONDEP: no treatment;

- DEPCEN: centralised treatment plant;

- DEPAZI: farm treatment systems;

- DEPSET: decentralised purification system based on real time monitoring of water quality.

\subsection{The MULINO approach for the analysis of alternative irrigation systems}

The typical application context for the MULINO methodology and the mDSS software is defined in terms of a decision in the field of sustainable natural resources management and in particular in the IWRM field. The methodology is inspired by the principles of the WFD and has been designed with water authorities as the target users, and its application foresees the involvement of decision makers, experts and 


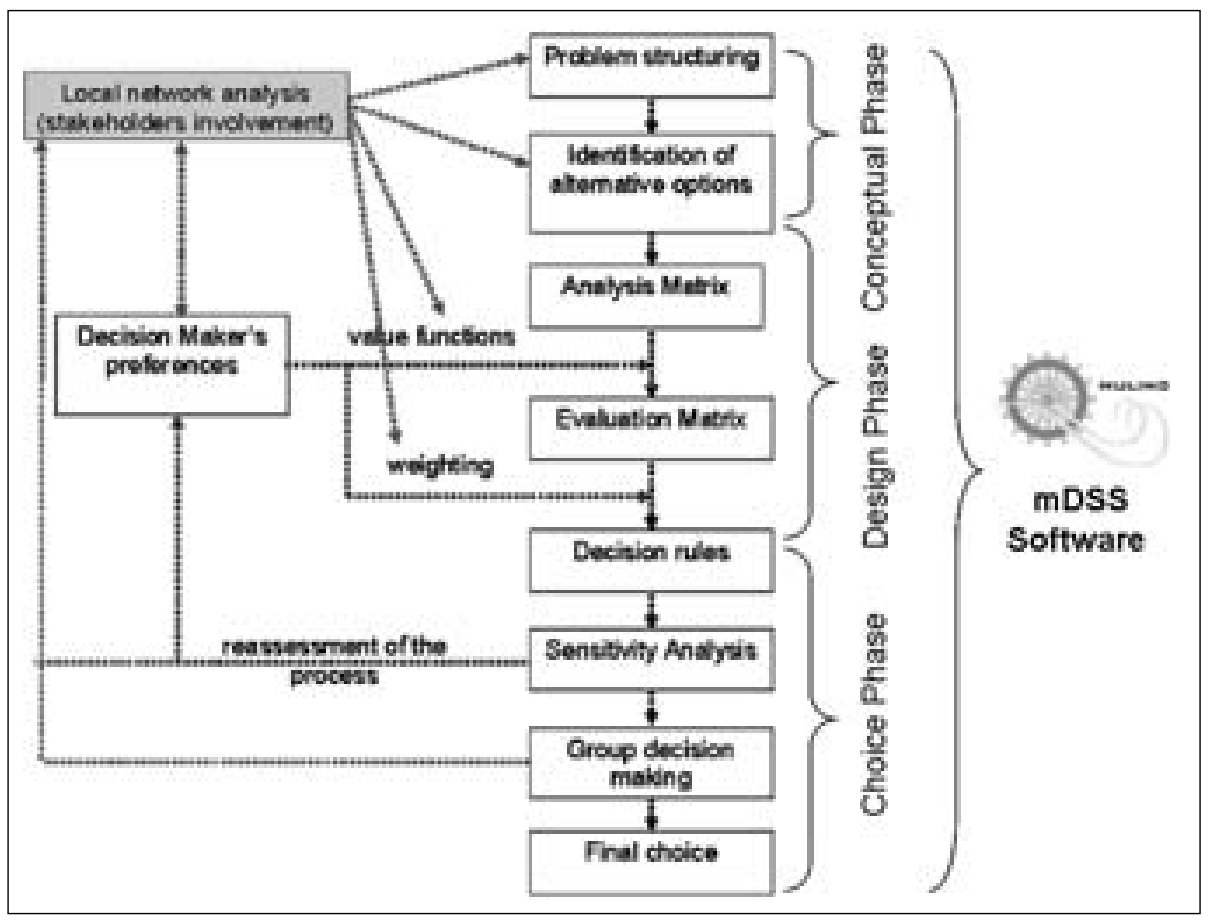

Figure 2. Flowchart of the MULINO methodology.

stakeholders. According to the requirements of the WFD, the approach developed by the project specifically targets the support of the competent authority in managing the planning or decision processes with the active involvement of interested stakeholders (Article 14 of the WFD).

The MULINO methodology leads the user (i.e. the decision maker, DM) through a process that begins with describing and structuring a water management problem, information sharing among selected stakeholders, and finishes with identifying a final choice between possible alternative solutions to the problem (Figure 2).

The involvement of stakeholders begins with the analysis of social networks that serves to disclose the existing relationships between the various actors (including the decision makers) involved in water uses and management within the area interested by the decision to be taken (e.g. a new project or plan). Very importantly, the Social Network Analysis (SNA) as implemented in the MULINO approach, gives the opportunity to identify efficient means for considering the different opinions in the decision process (e.g. the weighting of decision criteria, as described below) and, later on, for implementing them in the decision to be taken.

According to the MULINO methodology, the main stakeholders are initially selected by the competent administration, in this case the $\mathrm{BPB}$, and they may in turn suggest others to be involved (the so-called snow-ball technique). The collection of information about the local network is based upon questionnaires (Q2) compiled by interviewing the selected stakeholders. The questionnaires, designed by the sociologists involved in the project (see Rodrigues et al., 2006, for more details) analyse the local social networks, the relations between actors, in terms of intensity and purpose, and between the stakeholders in the study area. The questionnaires are also aimed at investigating the stakeholders' knowledge about the identified problems, their ideas about existing alternative options, and the criteria to be considered in the choice - as well as their weights.

The data collected in Q2 allow to build a sociomatrix, i.e. a matrix depicting the intensity of social relations within local networks, grouped in six classes ranging from 0 (no relationship existing) and 4 (very frequent - almost daily - contacts). The sociomatrix and other information about social networks were analysed by means of the AGNA (Applied Graph \& Network Analysis) software, which provides the following capabilities:

- visual representation of the local network, 
that also allows clustering various interest groups existing in the network;

- computation of various parameters that characterise the network, such as;

- distances between members of the network (Network diameter, eccentricity, the geodesic matrix, shortest path between individuals);

- sociometric parameters such as nodal degree, density and cohesion of the network, emission, reception and determination degrees, and sociometric status of each individual of the network.

Having analysed the local networks, the MULINO approach envisages the use of mDSS as a means for managing and communicating the whole decision process, culminating with the identification of the preferred choice within a finite set of options, through the implementation of Multi-Attribute Analysis (MAA) methods. According to Simon (1960), mDSS guides the user through three decision phases: "Intelligence, or Conceptual phase", "Design phase" and "Choice phase".

In a typical application, the first step is to identify the study area. Once this has been done, its socio-economic and environmental characteristics are described according to the DPSIR conceptual framework (Driving forces, Pressures, State, Impact and Response) (EEA, 1999). Causal relationships and dynamic interactions within the area are conceptualised in a procedure through which the user is asked to construct DPS "chains" in order to identify the main cause-effect relationships between human activities, described by $\mathrm{D}$ and $\mathrm{P}$ indicators, and the state, or change of state, of water resources (S indicators). This first phase is termed "Conceptual Phase". The MULINO methodology introduces a local network study to be completed through a series of interviews with selected stakeholders, and the application of modelling tools to analyse the dynamic aspects of the water cycle. The decision maker can thus structure the problem in collaboration with stakeholders, through a questionnaire targeted to the decisional problem in question. The socio-economic and environmental information is stored in appropriate catalogues and organised according to the DPSIR approach in various formats allowing the user to deal with spatial and temporal data series.

The user is then ready to enter the "Design
Phase" where he/she describes the alternative options, selects the decisional criteria taking into account the results of the local network analysis, and the results of data coming from surveys, census, monitoring and modelling are stored in the Analysis Matrix (AM). The AM is structured with options in the columns and decisional criteria in the rows. Criteria are quantified by means of the indicators selected within the DPSIR conceptual framework built in the Conceptual phase.

The evaluation, normalisation and weighting of the multidimensional data stored in the AM take the decision maker to the "Choice Phase" in which the Evaluation Matrix (EM) is built, and one or more decision rules are applied to identify the "best" option. Local network questionnaires are designed to support public participation by collecting structured information about stakeholders' preferences that relate to the decision problem. These preferences can be combined in the mDSS's group decision-making routine.

In this final phase, the mDSS software allows the user to analyse how the variables influence the selection of the preferred option through the sensitivity analysis and, finally, a "sustainability chart" is provided to assess the balancing of social, economic and environmental performances of the various options (more details about MULINO and mDSS can be found in the MULINO Project, 2004).

\section{Results}

\subsection{Analysis of the altenative abstraction and dis- tribution systems}

As previously stated, the results of the EIA previously carried out by the BPB were elaborated to be implemented in the mDSS, in order to allow for more efficient data processing and communication with the interested parties. The judgements expressed by the experts regarding the performances of the 6 possible options for water abstraction and distribution (originally scaled between -3 and +3 , as reported in Table 2) were normalised to fall between 0 and +1 using simple benefit type value functions, to provide the values for the mDSS Evaluation Matrix. The decision maker preferences were further investigated by eliciting the weights to be assigned to each decision criterion using a hierar- 
Table 2. Analysis matrix of Step 1: abstraction and distribution options.

\begin{tabular}{|c|c|c|c|c|c|c|}
\hline \multirow[b]{2}{*}{ CRITERIA } & \multirow[b]{2}{*}{$1 \mathrm{~A}$} & \multicolumn{5}{|c|}{ OPTIONS } \\
\hline & & 1B & $2 \mathrm{~A}$ & $2 \mathrm{~B}$ & $2 \mathrm{C}$ & $3 B$ \\
\hline Quality of abstracted water & 1 & 1 & 3 & 3 & 3 & 3 \\
\hline Quality of transported water & 3 & 3 & 3 & 3 & -1 & 3 \\
\hline Impact with the river ecosystem & -3 & -3 & 0 & 0 & 0 & 0 \\
\hline Punctual landscape impact & -1 & -1 & 0 & 0 & 0 & -2 \\
\hline Lineal landscape impact & 3 & 2 & 3 & 2 & -1 & 2 \\
\hline Socio-econ. impact of abstraction system & 3 & 3 & 2 & 2 & 2 & 1 \\
\hline Socio-econ. impact of distribution system & 2 & -1 & 2 & -1 & 3 & -1 \\
\hline Losses in the network-efficiency & 3 & 2 & 3 & 2 & -1 & 2 \\
\hline Material and installation costs & 3 & 2 & 3 & 2 & -1 & 2 \\
\hline
\end{tabular}

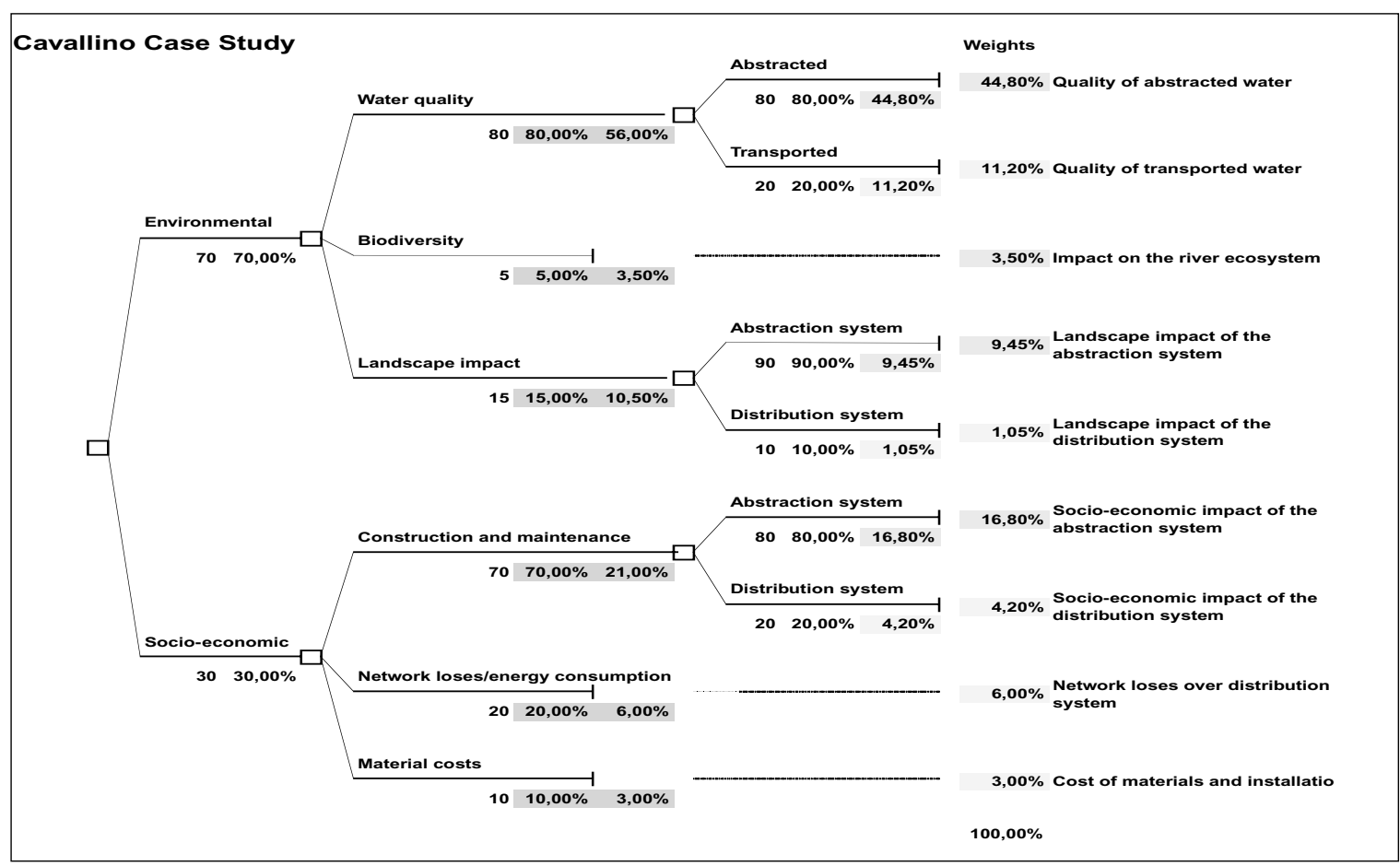

Figure 3. Results of the hierarchical weighting procedure (Step 1).

chical approach. Firstly, the DM was asked to assess the weights of two macro-criteria (environment and socio-economics). After that, for each macro-criterion, the DM was asked about the relative importance of the criteria within the two macro-criteria, and so on for the three hierarchical levels. The final weights were calculated by multiplying the criterion weight by the relative weights until the last level of criteria (Figure 3$)^{2}$.

\footnotetext{
2 This top-down weighting procedure was more intuitive for the DM, when several criteria should be considered, because it appeared to be very difficult to express the set of weights to a very long list of criteria at the same time.
}

Having defined the contents of the EM and the criterion weights, decision rules were used to compare the different options. The evaluation using Simple Additive Weighting shows that option $2 \mathrm{~A}$ should be preferred, i.e. the utilisation of an existing pumping station along the Sile River to divert water to the Cavallino Penisula by means of a cement pipe. Even if it is difficult to say that the differences are determinant, one can certainly conclude that option 2 (the water abstraction place) is dominant. This would suggest further analysis to obtain more precise data about the distribution system starting from the abstraction point 2 . The evaluation using 


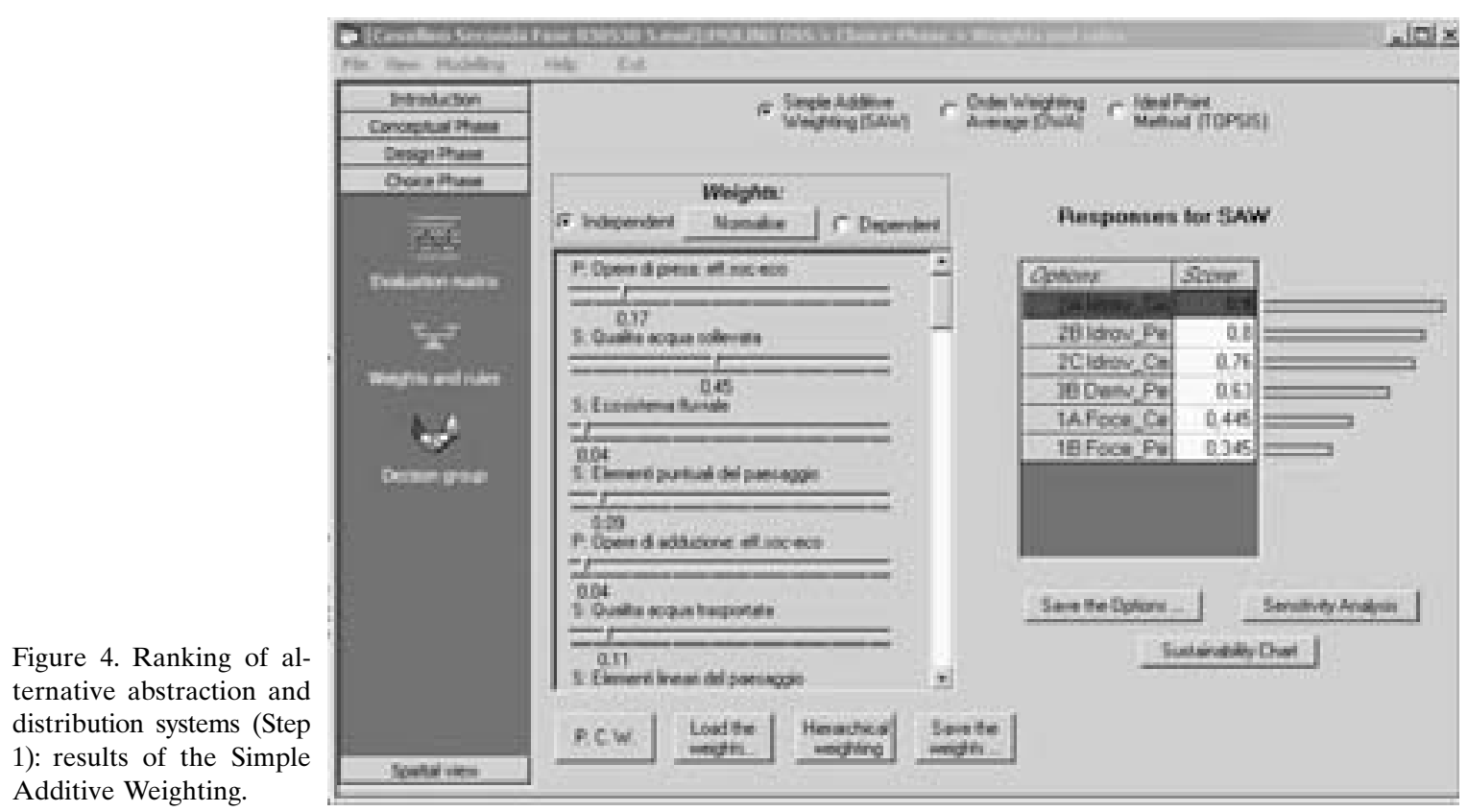

other decision rules gave the same results as the Simple Additive Weighting, thus supporting the idea about the robustness of the ranking. Figure 4 shows the ranking of the options through the interface of mDSS.

\subsection{Selection of most suitable option for water treatment}

Amongst the efforts for establishing fruitful communication and collaboration with stakeholders of the Cavallino Peninsula, the abovementioned farm survey was preliminarily carried out to define Step 2 of the decision process. The main results about the part of the questionnaire (Q1) targeted to the farmers' perception of the planned aqueduct show that $98 \%$ of them were informed about the project, mainly through their associations that informed them. They were informed also about the expected long-term environmental impacts of the current irrigation system, that motivated the reorganisation project. The majority of the farmers $(71 \%)$ perceived problems in their sector mainly related with soil availability, drainage and water quality, but the main issues expected from the project are related with water quality, water availability and economic impacts in their activities. Having identified the water quality issue as the main focus of the following step of the study, it appeared clear that the main insti- tutions involved in water management were to be involved in the participatory process, through the Social Network Analysis (SNA). The BPB was included in the interviews to allow for acquiring information about the existing networking and, in case, for identifying possible strategies for improving relationships and communication with the various stakeholders.

The analysis of the sociomatrix produced with the questionnaires and the elaboration provided by the AGNA software allowed for identifying the intensity of communication between stakeholders and for clustering of stakeholders after analysing the network for frequent (3) and very frequent (4) interactions between individuals.

Three important clusters of entities (individuals or groups/institutions) with intensive communication ties can be identified from the image:

- Cluster A - Groups or individuals involved in the use of water for agricultural purposes:

- Farmers and agricultural associations (entities 2, 3, 6 and 8 in figure 5);

- Land Reclamation Board (also end user);

- Municipal administration of Cavallino Treporti.

- Cluster B - Environmental decision makers at the regional level: 


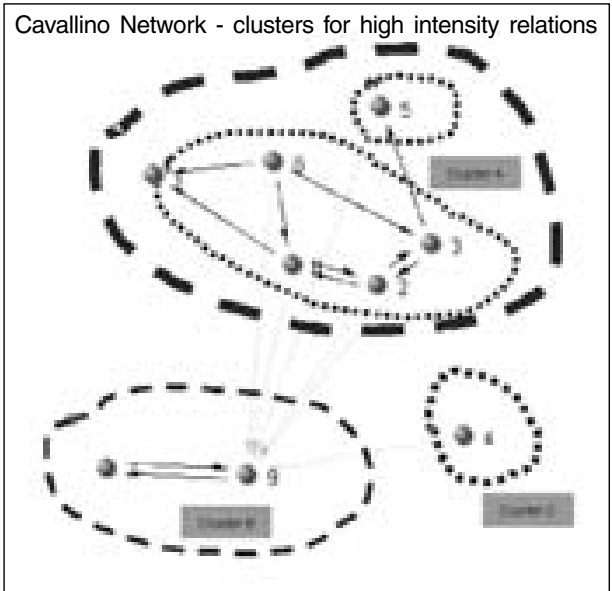

\begin{tabular}{|l|l|}
\hline 1 & Consorzio di Bonifica (Decision maker) \\
\hline 2 & Farmer 1 \\
\hline 3 & Farmer 2 \\
\hline 4 & Civil Engineers Regional Office \\
\hline 5 & Municipal Administration Cavallino-Treporti \\
\hline 6 & Confederazione Italiana Agricoltori \\
\hline 7 & Veneto Region - Dept. Special Law for Venice Lagoon \\
\hline 8 & Coldiretti \\
\hline 9 & Veneto Environmental Protection Agency \\
\hline
\end{tabular}

Figure 5. Intensity of the local network.

Table 3. Evaluation Matrix. Step 2.

\begin{tabular}{lcccc}
\hline CRITERIA & NONDEP & DEPCEN & DEPAZI & DEPSET \\
\hline Quality of water & 0.04 & 0.15 & 0.51 & 0.30 \\
Investment costs & 0.62 & 0.06 & 0.19 & 0.14 \\
Maintenance costs & 0.64 & 0.05 & 0.11 & 0.21 \\
Ease to manage & 0.69 & 0.16 & 0.06 & 0.10 \\
\hline
\end{tabular}

- Veneto Region - Dept. for Special Law for the Venice Lagoon;

- Veneto Environmental Protection Agency.

- Cluster C - Regional Civil Engineers Department ${ }^{3}$.

Regarding the Density of the network, which represents the actual number of connections reported to the total - and theoretic - number of available connections, the Cavallino network ( 0.75 - in the value range 0,1 ) was observed to be high, thus showing that most of the available connections between individuals are practically used.

Regarding the Cohesion parameter (an index showing the degree of reciprocity of the connections, i.e. the actual number of reciprocal connections divided by the total number of possible reciprocal connections), the Cavallino network once again showed a high value, with a cohesion index of 0.61 (higher than 0.5).

\footnotetext{
${ }^{3}$ This can be considered as a cluster by itself, as it represents the regional authority that delivers technical permits for water abstraction from wells, being thus in a not frequent contact with none of the other individuals of the Cavallino local network.
}

More information about the Sociometric Status (i.e. the intensity of communication of an individual with the other partners with whom he/she is in direct contact) and the identification of shortest communication paths from end user to stakeholders were calculated for the use of $\mathrm{BPB}$, and are not reported here for brevity. Worth to note is the fact that, given the limited size of the area, the social actors involved in the network showed to have good opportunities to communicate directly, without intermediaries.

Having defined the structure of the local networks, the analysis matrix was obtained from the BPB experts by using a pairwise comparison for each criterion, based on their knowledge and experience. The value functions were constructed using the benefit type shape, from which the evaluation matrix reported in Table 3 was obtained.

Stakeholders being grouped according to the clusters described above, the results of Q2 were processed to derive the values of weights expressing the preferences per social group. Thus, the result of each weight of criteria is the arithmetic average of the weights expressed by each 
Table 4. Aggregated weights of criteria by cluster.

\begin{tabular}{lccccc}
\hline & \multicolumn{3}{c}{ CLUSTERS } & & C \\
& \multicolumn{2}{c}{ B } & \multicolumn{2}{c}{ WEIGHTS } \\
\hline CRITERIA & Average & Average & S.D. & Average value & S.D. \\
\hline Water quality & $0.00 \%$ & $26.78 \%$ & 0.07127 & $39.76 \%$ & 0.144834 \\
Ease to manage & $29.17 \%$ & $24.31 \%$ & 0.086642 & $27.51 \%$ & 0.206351 \\
Maintenance cost & $29.17 \%$ & $19.86 \%$ & 0.088039 & $12.23 \%$ & 0.118088 \\
Cost of investment & $29.17 \%$ & $13.34 \%$ & 0.004192 & $12.23 \%$ & 0.118088 \\
\hline
\end{tabular}

of the interviewees belonging to the same cluster. Table 4 presents the averages and standard deviations of the weights expressed by the clusters.

As pointed out by Q1, water quality is a production factor of primary importance for the horticultural systems located in the Cavallino Peninsula. It thus becomes of uppermost importance for the cluster involved in agriculture (almost 40\%). It is also of high importance for environmental regional organisations, that take into account more criteria than the individuals in the agricultural cluster did (the more criteria we have - the lower is the relative weight).

In the case of environmental decision makers, water quality is now seen more like a raw material, as the evaluation of water quality as an environmental criterion was made in the previous step of the analysis. The cluster consisting only of the Civil Engineers Dept. from the Veneto Region pays no attention at all to water quality, as the subject lies outside their re- sponsibilities. They focus mainly on the costs (both investment and maintenance) involved by the project - and consider also the project's manageability more than the other clusters.

Having defined the contents of the AM for the second step of the analysis and the weights of criteria, the last phase of the decision process was the identification of the preferred option for water treatment. Here the results of social network analysis were used to compare the preferences of the three groups of stakeholders representing different points of view about the problem.

Simple Additive Weighting was used for the comparison of the alternatives because it is the simplest and the most comprehensible one for all types of stakeholders. The ranking obtained by the different sets of weights, as shown in Figure 6 , was similar, demonstrating that, notwithstanding the different opinions about the problem in question, all the groups concluded that the preferred solution should be to avoid any investment in treatment plants.

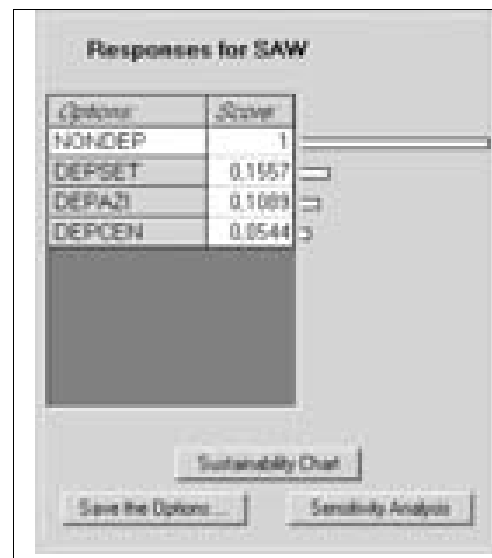

Results of mDSS for Cluster 1
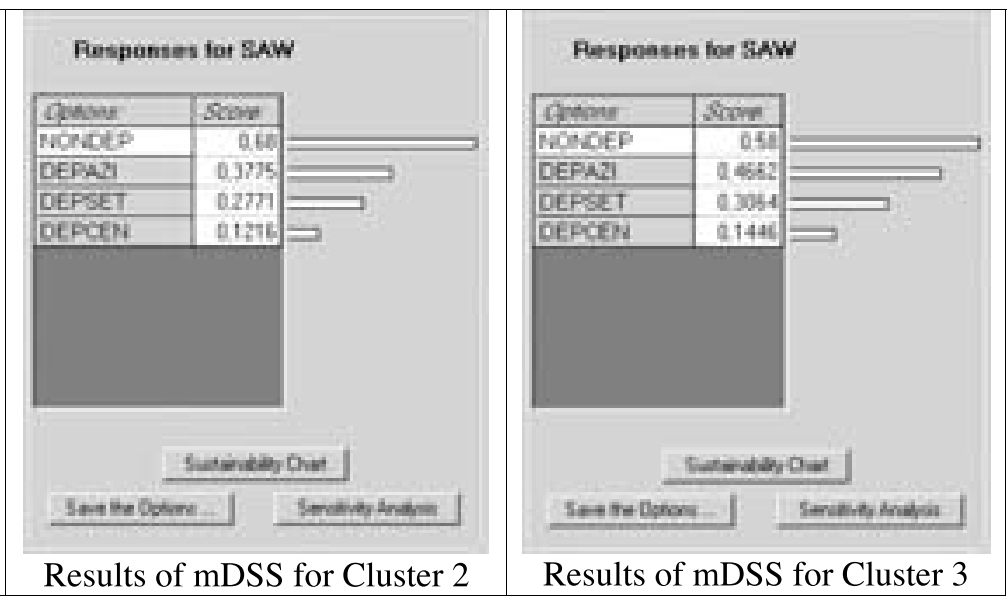

Figure 6. Results of the Simple Additive Weighting according to the preferences of the various social clusters for what concerns water treatment (Step 2). 


\section{Concluding remarks}

The MULINO approach and, in particular, the combination of SNA and the mDSS tool, showed potentials to formalise and standardise the decision process, thus allowing parallel, but coherent and comparable, decision processes to be carried out by different stakeholders. The mDSS tool was useful for working at the interface between technical and political "bodies" within the administration, and for supporting the political side, by facilitating the introduction of more transparency and efficient communication. It served to implement both the results of the Environmental Impact Assessment and those of the analysis of alternative options for water treatment.

This study demonstrated also the usefulness of the mDSS when confronting the preferences of a range of stakeholders.

On the other hand it appeared clear that the implementation of mDSS requires a trained user, i.e. a motivated user with time available to invest in learning how to use the tool and the description of DPS chains, though providing a useful support for clarifying the decision background and its interpretation by the decision makers, showed to be in some cases subjective or ambiguous.

Public participation was rather unusual in the area, at least as a structured and formalised process. If found a positive attitude for collaboration both within the farmers and among the institutions involved in the process. Unfortunately, difficulties found by the project at higher decisional levels in the implementation of the choices made, which slowed down the realisation of the project, could negatively affect the credibility of participatory approaches in future cases. Efficient communication wit all the involved parties could limit these negative consequences.

\section{Acknowledgements}

Research carried out with the financial contribution of the Project MULINO (MULti-sectoral, INtegrated and Operational Decision Support System for Sustainable Use of Water Resources at the Catchment Scale), funded under the Fifth Framework Programme of the European Union (EVK1-2000-00082). The authors gratefully acknowledge the contribution of Mr. Luca Dridani for the farm survey.

\section{References}

Andreu J., Capilla J., Sanchis E. 1996. AQUATOOL - a generalized DSS for water-resources planning and operational management. Journal of Hydrology, 177:269-291.

Catelli C., Pani G., Todini E. 1998. FLOODSS, Flood operational DSS. In: Balabanis P., Bronstert A., Casale R., Samuels P. (eds.): Ribamod: River basin modelling, management and flood mitigation.

da Silva L.M., Park J.R., Keatinge J.D.H., Pinto P.A. 2001. The use of the DSSIPM in the Alentejo region of the southern Portugal. Agricultural Water Management, 51:203-215.

Dridani L. 2002. Analisi territoriale come supporto alle decisioni per la gestione dell'irrigazione nella penisola del Cavallino (VE). Tesi di laurea, Università di Padova, Facoltà di Agraria, a.a. 2001-02.

EC (European Communities) 2000. Directive 2000/60/EC of the European Parliament and of the Council Establishing a Framework for Community Action in the Field of Water Policy (OJ L 327, 22.12.2000).

EEA (European Environmental Agency) 1999. Environmental indicators: typology and overview. Technical Report No 25, EEA, Copenhagen.

ICSU (International Council for Science) 2002. Making Science for Sustainable Development More Policy Relevant: New Tools for Analysis, ICSU Series on Science for Sustainable Development, no. 8.

Jamieson D.G., Fedra K. 1996. The "WaterWare" decision-support system for river-basin planning. 1. Conceptual design. Journal of Hydrology, 1977:163-175.

Lahdelma R., Salminen P., Hokkanen J. 2000. Using multicriteria methods in environmental planning and management. Environmental Management, 26:595605.

O’Callaghan 1995. NELUP: An introduction. Journal Environmental Planning and Management, 38:5-20.

Ostrowski M.W. 1997. Improving sustainability of water resources systems using the group decision support system STEEL-DSS. Research Report at Darmstadt University of Technology.

Rodrigues L., Russo Machado C., Lourenço N. 2006. Social networks and the management of water resource for agriculture. The example of Rio Caia Catchment (Portugal). Italian Journal of Agronomy, 4:741-756.

MULINO Project. 2004. Final documents and software tool. Available online at: http://siti.feem.it/ mulino/

Simon H.A. 1960. The New Science of Management Decision. Harper and Brothers, New York. 